\title{
Clinical, biochemical, and genetic predictors of coronary artery bypass graft failure
}

\author{
Bobby Yanagawa, MD, PhD, ${ }^{a}$ Khaled D. Algarni, MD, MHSc, ${ }^{\text {a,b }}$ Steve K. Singh, MD, MSc, ${ }^{c}$ \\ Saswata Deb, MD, ${ }^{\mathrm{a}}$ Jessica Vincent, DipClinEpi, ${ }^{\mathrm{a}}$ Randi Elituv, BSc, ${ }^{\mathrm{a}}$ Nimesh D. Desai, MD, PhD, ${ }^{\mathrm{d}}$ \\ Karthikeyan Rajamani, PhD, ${ }^{\mathrm{e}}$ Bruce M. McManus, MD, PhD, ${ }^{\mathrm{e}}$ Peter P. Liu, MD, MSc, ${ }^{\mathrm{f}}$ \\ Eric A. Cohen, MD, ${ }^{\mathrm{g}}$ Sam Radhakrishnan, MD, ${ }^{\mathrm{g}}$ James D. Dubbin, MD, ${ }^{\mathrm{g}}$ Leonard Schwartz, MD, ${ }^{\mathrm{f}}$ and \\ Stephen E. Fremes, MD, MSc ${ }^{\mathrm{a}}$
}

Objectives: To identify novel predictors for coronary artery bypass grafting failure, we probed for associations with known clinical and biochemical risk factors for atherosclerosis. We also used microarray analysis to identify novel single nucleotide polymorphisms to better understand the genetics and pathogenesis of graft occlusion.

Methods: The present study was a nested case-control substudy of the Radial Artery Patency Study 5-year
follow-up data. From 1996 to 2001,87 patients underwent coronary artery bypass grafting. Of these, 26 patients
( $29.9 \%$ ) had an occluded study graft (saphenous vein or radial artery) at $8.0 \pm 1.1$ years. The clinical parameters,
late angiography, blood biomarker levels, and surgical outcomes data were included in a multivariate analysis to
determine the independent predictors of graft failure.

Results: The risk factors of graft failure were fibrinogen (odds ratio [OR], 3.94; 95\% confidence interval [CI], $1.33-11.63 ; P=.01$ ), creatinine (OR, $1.06 ; 95 \% \mathrm{CI}, 1.02-1.10 ; P=.006)$, and diabetes mellitus (OR, 5.15; $95 \%$ CI, $1.08-24.59 ; P=.04)$. High-density lipoprotein (OR, $0.74 ; 95 \%$ CI, $0.53-1.02 ; P=.06$ ) was weakly protective; however, low-density lipoprotein and total cholesterol were not predictors. We then identified the association of several human single nucleotide polymorphisms with graft failure, including mutations in glutathione-S-transferase $\alpha 3$. Human coronary arteries and bypass grafts demonstrated increased protein expression of glutathione-S-transferase $\alpha 3$, a known cardioprotective factor, in the atherosclerotic regions and surrounding adventitial tissues.

Conclusions: We identified diabetes as a potential clinical predictor and plasma fibrinogen, creatinine, and high-density lipoprotein as potential novel biomarkers. These might help risk stratify patients for the development of graft failure. We also demonstrated a novel association between glutathione-S-transferase $\alpha 3$ and graft failure. (J Thorac Cardiovasc Surg 2014;148:515-20)

\section{Supplemental material is available online.}

\footnotetext{
From the Divisions of Cardiac Surgery and Cardiology, ${ }^{\mathrm{g}}$ Schulich Heart Centre, Sunnybrook Health Sciences Centre, University of Toronto, Toronto, Ontario, Canada; King Fahad Cardiac Center, ${ }^{\mathrm{b}}$ King Saud University, Riyadh, Saudi Arabia; Hamilton Health Sciences Centre, ${ }^{\mathrm{c}}$ Hamilton, Ontario, Canada; Penn Heart and Vascular Center, ${ }^{\mathrm{d}}$ Perelman Center for Advanced Medicine, Philadelphia, Pa; Institute of Heart and Lung Health, ${ }^{\mathrm{e}}$ St Paul's Hospital, Vancouver, British Columbia, Canada; and Division of Cardiology, ${ }^{\mathrm{f}}$ Toronto General Hospital, Toronto, Ontario, Canada.

This work was funded by a grant from the Canadian Institutes of Health Research (CIHR) \#MOP-74707. S.D. is a Vanier Canada Graduate Scholar, CIHR, and S.E.F. is the Bernard S. Goldman Chair in Cardiovascular Surgery.

Disclosures: Authors have nothing to disclose with regard to commercial support. Presented at the 2012 American Heart Association Conference, Los Angeles, California. Received for publication Aug 11, 2013; revisions received Sept 21, 2013; accepted for publication Oct 6, 2013; available ahead of print Dec 10, 2013.

Address for reprints: Stephen E. Fremes, MD, MSc, Bernard S. Goldman Chair in Cardiovascular Surgery, Division of Cardiac Surgery, Schulich Heart Centre, Sunnybrook Health Sciences Centre, 2075 Bayview Ave, Suite H-410, Toronto, ON M4N 3M5, Canada (E-mail: stephen.fremes@sunnybrook.ca). $0022-5223 / \$ 36.00$

Copyright (C) 2014 by The American Association for Thoracic Surgery http://dx.doi.org/10.1016/j.jtcvs.2013.10.011
}

Coronary artery bypass grafting (CABG) is an effective treatment of complex, multivessel coronary artery disease. ${ }^{1}$ Graft failure is a surrogate marker for future cardiac events, including repeat revascularization, myocardial infarction, and death. ${ }^{2,3}$ The multi-institutional Collaborative Study in Coronary Artery Surgery found several clinical and angiographic patient characteristics predictive of graft occlusion, such as age, female gender, and left ventricular dysfunction. ${ }^{4}$ However, the identification of patients at risk of graft failure continues to be challenging.

The development of a clinically validated panel of biomarkers to predict graft occlusion would have the potential to facilitate perioperative measures to prevent myocardial injury and add valuable prognostic information by predicting the risk of mortality after CABG. In the present report, we evaluated the known clinical variables and plasma levels of the biomarkers of atherosclerosis using long-term angiograms to identify novel associations that could potentially be used for the prediction of graft occlusion after CABG. Furthermore, given that $30 \%$ to 


$$
\begin{aligned}
& \text { Abbreviations and Acronyms } \\
& \begin{aligned}
\text { CABG } & =\text { coronary artery bypass grafting } \\
\text { CI } & =\text { confidence interval } \\
\text { CTA } & =\text { computed tomography angiography } \\
\text { GST } \alpha 3 & =\text { glutathione-S-transferase } \alpha 3 \\
\text { HDL } & =\text { high-density lipoprotein } \\
\text { LDL } & =\text { low-density lipoprotein } \\
\text { OR } & =\text { odds ratio } \\
\text { SNP } & =\text { single nucleotide polymorphism } \\
\text { SVG } & =\text { saphenous vein graft }
\end{aligned}
\end{aligned}
$$

$60 \%$ of the individual risk of coronary artery disease is hereditary, it is also likely that graft occlusion is influenced by genetics. ${ }^{5}$ Thus, we performed a case-control genomewide association study to identify novel single nucleotide polymorphisms (SNPs) associated with graft failure that might lead to the identification of genetic predictors of graft occlusion and novel pathogenetic molecules.

\section{METHODS \\ Study Design}

The present study was a nested case-control substudy of the Radial Artery Patency Study (NCT00187356). ${ }^{6}$ This multicenter study involved 561 patients initially enrolled across 13 sites, of whom 269 patients underwent late angiography or computed tomography angiography (CTA). A total of 87 patients from a single site participated in the present substudy (of 252 total patients and 150 total patients with late angiograms or CTA). In brief, each patient had received both a radial artery graft and a study saphenous vein graft (SVG), and follow-up examinations were performed at $8.0 \pm 1.1$ years using angiography $(\mathrm{n}=74)$ or CTA $(\mathrm{n}=13)$. Peripheral blood samples were taken at follow-up angiography or CTA for biomarker analysis. All angiograms and CTAs were reviewed by an independent committee of 4 experienced cardiologists who were unaware of patient randomization (E.A.C., S.R., J.D.D., L.S.). Cases were defined as patients with $\geq 1$ study grafts that were completely occluded. Controls were defined as patients with patency of both study grafts. The primary study objective was to identify the clinical variables, circulating biomarker levels, and surgical outcomes data associated with bypass graft occlusion. Our institutional review committee approved the present study, and all subjects gave written informed consent.

\section{Sample Collection and Biochemical Assay}

The peripheral blood samples were centrifuged (15 minutes, $3000 \mathrm{rpm}$ ) and analyzed in triplicate for high-sensitivity C-reactive protein (Roche Diagnostics, Basel, Switzerland), fibrinogen (Roche Diagnostics), homocysteine (Roche Diagnostics), interleukin-6 (R\&D Systems, Minneapolis, Minn), interleukin-18 (MBL, Co, Ltd, Nagoya, Japan), lipoprotein a (Abcam, Cambridge, Mass), total cholesterol (Roche Diagnostics), high-density lipoprotein (HDL; Roche Diagnostics), lowdensity lipoprotein (LDL; Roche Diagnostics), apolipoprotein B (Roche Diagnostics), and triglycerides (Roche Diagnostics).

\section{DNA Extraction and SNP Characterization}

Peripheral blood leukocytes were collected from flash frozen samples. The DNA was extracted (DNeasy kit, Qiagen, Hilden, Germany) and multiplex polymerase chain reaction performed. Purified primer extension reactions were submitted for hybridization to the Illumina 660W-Quad Infinium DNA Analysis BeadChips (San Diego, Calif). The criteria for SNPs were a call rate $>95 \%$, SNPs in Hardy-Weinberg equilibrium in control $(P<.0001)$, a minor allele frequency $>1 \%$, and individual samples with a genotype presence $>95 \%$.

\section{Immunohistochemistry}

Formalin-fixed and paraffin-embedded human coronary artery and bypass graft tissues from the autopsy cases were submitted for immunohistochemistry using anti-glutathione-S-transferase $\alpha 3$ (GST $\alpha 3 ; 1: 5000$; Abcam, Cambridge, Mass), biotinylated secondary antibody (1:10,000), and Vector Black Alkaline Phosphatase Substrate Kit (Vector Laboratories, Burlingame, Calif). All sections were reviewed by a cardiovascular pathologist (B.M.M.). Quantitative imaging analysis was performed using ImageProPlus (Media Cybernetics, Rockville, Md). The positive and negative controls are shown in Figure E1.

\section{Statistical Analysis}

Statistical analyses were performed with SPSS (IBM, Somers, NY). Univariate analyses were performed using the $\chi^{2}$ or Fisher exact test for categorical variables, an independent 2-sample $t$ test for normally distributed continuous variables, and Wilcoxon rank sum test for continuous variables, with a nonparametric distribution. The variables with univariate $P<.25$ or those of known clinical importance were included in a multivariable logistic regression model to calculate the risk-adjusted predictors of graft occlusion. Model discrimination was evaluated by the area under the receiver operating characteristic curve, and calibration was assessed using the Hosmer-Lemeshow goodness-of-fit statistic $(P=.7) .^{7}$ The model was evaluated for collinearity using the variance inflation factor, in which multicollinearity is considered positive if the variance inflation factor is $>2.5$. All variance inflation factors in our model were $<2.5$. The data are presented as the median and range or mean \pm standard deviation.

\section{RESULTS}

\section{Patient Characteristics, Preoperative Details, and Operative Outcomes}

A total of 87 patients who had undergone CABG from June 1996 to January 2001 were enrolled in the present study. The baseline characteristics of the total study population at enrollment are listed in Table 1. The cases had greater baseline creatinine levels than the controls $(97.0 \pm 21.2$ vs $88.1 \pm 17.1 ; P=.05)$.

The intraoperative variables and postoperative outcomes are listed in Table 2. A trend was seen for a greater number of grafts in the case group than in the control group ( $3.9 \pm 0.7$ vs $3.6 \pm 0.6 ; P=.05)$ associated with a longer cardiopulmonary bypass time $(116.9 \pm 25.4$ vs $105.3 \pm$ 26.7 minutes; $P=.06)$. No in-hospital mortalities occurred.

\section{Late Angiography and CTA}

Angiography or CTA was performed at $8.0 \pm 1.1$ years of follow-up for all 87 patients, 7 of which were clinically directed. Of the 26 patients with an occluded study graft, $5(5.7 \%)$ had an occluded radial artery, $19(21.8 \%)$ an occluded SVG, and $2(2.3 \%)$ an occluded radial artery and SVG. Regarding the target vessels, of the occluded grafts, $16(57.1 \%)$ had been grafted to the circumflex artery and $12(42.9 \%)$ to the right coronary artery. 
TABLE 1. Baseline patient demographic information

\begin{tabular}{lccc}
\hline \multicolumn{1}{c}{ Variable } & $\begin{array}{c}\text { Control } \\
\text { group }\end{array}$ & $\begin{array}{c}\text { Case } \\
\text { group }\end{array}$ & $\begin{array}{c}\boldsymbol{P} \\
\text { value }\end{array}$ \\
\hline Patients (n) & 61 & 26 & \\
Age (y) & & & .6 \\
$\quad$ Mean & 60.7 & 61.7 & \\
$\quad$ Range & $42-75$ & $44-73$ & \\
Female gender & $28.8(21)$ & $35.7(5)$ & .8 \\
Preoperative myocardial infarction & $49.2(30)$ & $42.3(11)$ & .6 \\
Smoking & $75.4(46)$ & $76.9(20)$ & .6 \\
Hypertension & $59.0(36)$ & $50.0(13)$ & .5 \\
Dyslipidemia & $75.4(46)$ & $73.1(19)$ & .8 \\
Congestive heart failure & $3.3(2)$ & $3.8(1)$ & 1.0 \\
LVEF & & & \\
$\quad>60 \%$ & $52.5(32)$ & $46.2(12)$ & .6 \\
$\quad 40 \%$-60\% & $47.5(29)$ & $53.8(14)$ & \\
Diabetes mellitus & $27.9(17)$ & $42.3(11)$ & .2 \\
Creatinine $(\mu$ m/L) & $88.1 \pm 17.1$ & $97.0 \pm 21.2$ & .05 \\
Preoperative medications & & & \\
$\quad$ Aspirin & $83.6(51)$ & $84.6(22)$ & 1.0 \\
$\beta$-Blocker & $55.7(34)$ & $73.1(19)$ & .2 \\
Lipid lowering agent & $90.2(55)$ & $88.5(23)$ & 1.0 \\
ACEI/ARB & $68.9(40)$ & $57.7(15)$ & .3 \\
\hline
\end{tabular}

Data presented as $\mathrm{n}, \%(\mathrm{n})$, or mean \pm standard deviation. $L V E F$, Left ventricular ejection fraction; $A C E I$, angiotensin-converting enzyme inhibitor; $A R B$, angiotensin receptor blocker.

\section{Biomarkers}

Blood was submitted for expression of 12 circulating biomarkers previously associated with atherosclerosis (Table 3). Paradoxically, apolipoprotein B was significantly lower in the cases than in the controls $(0.69 \pm 0.15$ vs 0.79 $\pm 0.2 ; P=.03)$. No other significant differences were found in the biomarker levels between the case and control patients on univariate analysis. Regarding the lipid levels, $56.6 \%$ (47 of 83 patients) had an LDL $<2 \mathrm{mmol} / \mathrm{L}$ and $66.7 \%$ (42 of 63 patients) had an apolipoprotein B level $<0.8 \mathrm{~g} / \mathrm{L}$, meeting the current target for a high-risk patient subset (class I, level A evidence)

TABLE 2. Intraoperative and postoperative variables

\begin{tabular}{lccc}
\hline \multicolumn{1}{c}{ Variable } & $\begin{array}{c}\text { Control } \\
\text { group }\end{array}$ & $\begin{array}{c}\text { Case } \\
\text { group }\end{array}$ & $\begin{array}{c}\boldsymbol{P} \\
\text { value }\end{array}$ \\
\hline $\begin{array}{l}\text { Intraoperative variables } \\
\quad \text { Cardiopulmonary bypass time } \\
\quad(\mathrm{min})\end{array}$ & $105.3 \pm 26.7$ & $116.9 \pm 25.4$ & .06 \\
$\quad$ Crossclamp time (min) & $89.3 \pm 24.9$ & $96.1 \pm 29.2$ & .3 \\
$\quad$ Conduits (n) & $3.6 \pm 0.6$ & $3.9 \pm 0.7$ & .05 \\
Postoperative variables & & & \\
$\quad$ Hospital mortality (\%) & $0(0)$ & $0(0)$ & -3 \\
$\quad$ Stroke (\%) & $0(0)$ & $3.8(1)$ & .3 \\
$\quad$ Inotrope use (\%) & $11.5(7)$ & $7.7(2)$ & .7 \\
$\quad$ Ventilation duration (h) & $7.0(5.0-9.1)$ & $7.0(5.0-11.1)$ & .9 \\
Hospital stay (d) & $6.4 \pm 4.5$ & $8.7 \pm 5.4$ & .03 \\
Angiography after surgery (y) & $8.0 \pm 1.5$ & $8.0 \pm 1.3$ & .9 \\
\hline
\end{tabular}

Data presented as mean \pm standard deviation, \% (n), or median (interquartile range [25th-75th]).
TABLE 3. Plasma levels of circulating biomarkers in control and case groups

\begin{tabular}{lccc}
\hline \multicolumn{1}{c}{ Biomarker } & Control group & Case group & $\boldsymbol{P}$ value \\
\hline Apolipoprotein B $(\mathrm{g} / \mathrm{L})$ & $0.79 \pm 0.20$ & $0.69 \pm 0.15$ & .03 \\
C-reactive protein $(\mathrm{mg} / \mathrm{L})$ & $1.70 \pm 1.55$ & $1.91 \pm 1.93$ & .7 \\
Fibrinogen $(\mathrm{g} / \mathrm{L})$ & $3.19 \pm 0.63$ & $2.94 \pm 0.77$ & .2 \\
Total cholesterol $(\mathrm{mmol} / \mathrm{L})$ & $3.87 \pm 0.78$ & $3.73 \pm 1.17$ & .5 \\
HDL (mmol/L) & $1.03 \pm 0.38$ & $0.95 \pm 0.29$ & .3 \\
Total cholesterol/HDL ratio & $4.12 \pm 1.40$ & $4.40 \pm 2.88$ & .5 \\
LDL (mmol/L) & $2.09 \pm 0.73$ & $1.86 \pm 0.59$ & .2 \\
Triglycerides $(\mathrm{g} / \mathrm{L})$ & $1.68 \pm 0.98$ & $1.53 \pm 0.71$ & .9 \\
HbA1c & $0.06 \pm 0.01$ & $0.07 \pm 0.01$ & .1 \\
Lipoprotein a $(\mathrm{mg} / \mathrm{dL})$ & $12.0 \pm 12.1$ & $12.1 \pm 11.4$ & 1.0 \\
Homocysteine $(\mu \mathrm{mol} / \mathrm{L})$ & $13.4 \pm 4.8$ & $12.6 \pm 5.1$ & .5 \\
NT-BNP $(\mathrm{pmol} / \mathrm{L})$ & $372.0 \pm 456.2$ & $482.9 \pm 706.4$ & .4 \\
\hline
\end{tabular}

Data presented mean \pm standard deviation. $H D L$, High-density lipoprotein; $L D L$, low-density lipoprotein; $H b A l c$, hemoglobin Alc; $N T-B N P$, N-terminal brain natriuretic peptide.

according to the Canadian Lipid Guidelines. ${ }^{8}$ Regarding the secondary lipid targets, $51.8 \%$ (44 of 85 patients) had a total cholesterol/HDL ratio $<4.0$ and $64.7 \%$ (55 of 85 patients) had triglycerides $<1.7 \mathrm{mmol} / \mathrm{L}$.

\section{Predictors of Graft Occlusion}

The clinical parameters, circulating biomarker levels, and surgical outcomes data were included in a stepwise multivariate logistic regression analysis to find novel associations that might lead to independent predictors of graft failure. Of the biomarkers, fibrinogen was an independent predictor of graft failure (odds ratio [OR] 3.94; 95\% confidence interval $[\mathrm{CI}], 1.33-11.63 ; P=.01$; Table 4). HDL (OR, 0.74; $95 \% \mathrm{CI}, 0.53-1.02 ; P=.06)$ was weakly protective against graft failure, although this did not reach statistical significance. Regarding the preoperative characteristics, high creatinine $(\mathrm{OR}, 1.06 ; 95 \% \mathrm{CI}, 1.02-1.10 ; P=.006)$ and diabetes mellitus (OR, 5.15; 95\% CI, 1.08-24.59; $P=.04$ ) were predictive of graft failure.

\section{SNP Association With Graft Failure}

Genotypic analysis was performed for 26 case and 61 control patients. The SNPs with the strongest degree of association with graft failure are shown in Table E1. The SNP rs1330927, located on chromosome 9p21.3,

TABLE 4. Independent multivariate predictors of graft occlusion

\begin{tabular}{lcclc}
\hline \multicolumn{1}{c}{ Variable } & $\begin{array}{c}\text { Regression } \\
\text { coefficient }\end{array}$ & OR & \multicolumn{1}{c}{$\mathbf{9 5 \%}$ CI } & $\boldsymbol{P}$ value \\
\hline Fibrinogen & $1.37 \pm 0.55$ & 3.94 & $1.33-11.63$ & .01 \\
Creatinine & $0.54 \pm 0.02$ & 1.06 & $1.02-1.10$ & .006 \\
Diabetes mellitus & $1.64 \pm 0.80$ & 5.15 & $1.08-24.59$ & .04 \\
Preoperative $\beta$-blocker & $1.42 \pm 0.64$ & 3.17 & $1.06-13.2$ & .04 \\
HDL & $-0.31 \pm 0.17$ & 0.74 & $0.53-1.02$ & .06 \\
\hline
\end{tabular}

Reference values: fibrinogen, $1 \mathrm{~g} / \mathrm{L}$; creatinine, $1 \mu \mathrm{mol} / \mathrm{L} ; \mathrm{HDL}, 0.1 \mathrm{mmol} / \mathrm{L}$. $O R$, Odds ratio; $C I$, confidence interval; $H D L$, high-density lipoprotein. 

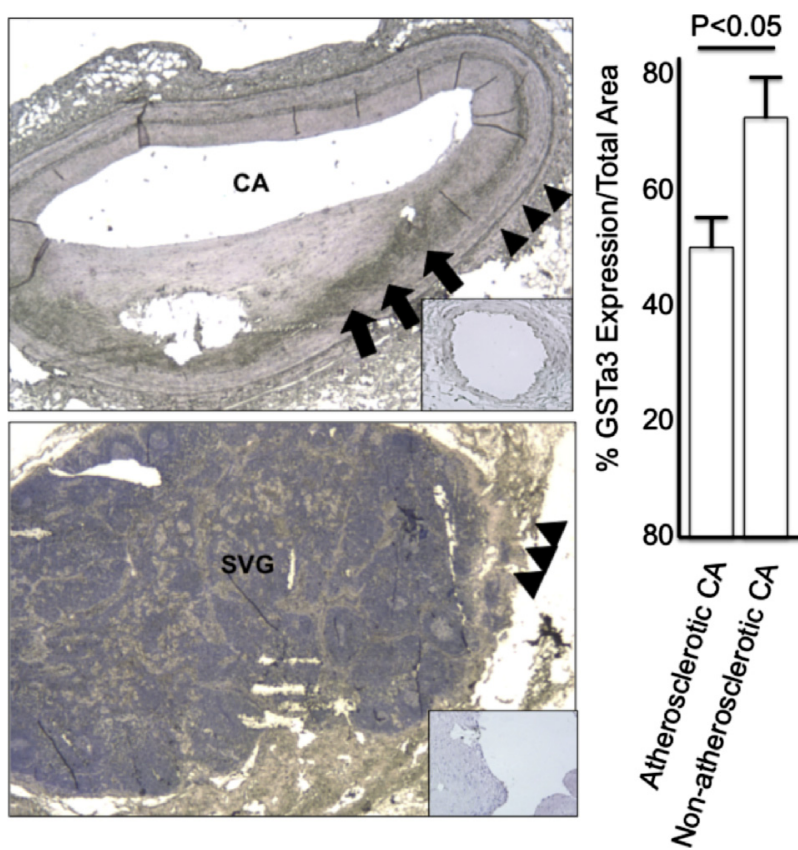

FIGURE 1. Glutathione-s-transferase $\alpha 3$ (GST $\alpha 3)$ expression in human coronary arteries (CAs) and saphenous vein grafts (SVGs). Upper, GST $\alpha 3$ expression seen in deep intimal layer (arrows) and adventitia (arrowheads) of atherosclerotic plaque regions of CA (original magnification $\times 4$ ) but not in the nonatherosclerotic CAs (Insert; original magnification $\times 40$ ). Lower, Gst $\alpha 3$ expression is present in the intima of the SVGs undergoing intimal proliferation (arrowheads; original magnification $\times 20$ ) but not in the patent vein grafts (Insert; original magnification $\times 20$ ). GSTA3 expression was more abundant in human atherosclerotic CAs $(\mathrm{n}=10)$ than in the nonatherosclerotic CAs on quantitative image analysis $(\mathrm{n}=6 ; P<.05)$.

a locus strongly associated with atherosclerosis, was significantly associated with graft occlusion. Also, 5 SNPs of the glutathione-s-transferase $\alpha 3$ (GST $\alpha 3$ ) gene, which encodes a key regulator of the protective response to oxidative stress, were found to be associated with graft failure.

\section{GST $\alpha 3$ Expression}

Atherosclerotic human coronary arteries $(n=10), C A B G$ grafts $(\mathrm{n}=10)$, and normal coronary arteries from patients with dilated cardiomyopathy $(\mathrm{n}=6)$ were evaluated for GST $\alpha 3$ protein expression. Expression of GST $\alpha 3$ was prominent in atherosclerotic human coronary arteries in the deep intimal and adventitial layers $(P<.05$; Figure 1$)$. In the human SVGs, GST $\alpha 3$ expression was demonstrated in the adventitial tissues in close special association with the occluded, but not the patent, grafts (Figure 1).

\section{DISCUSSION}

In the present report, we have attempted to identify novel associations among the clinical parameters, circulating biomarkers, and SNPs with graft failure after CABG.
We have demonstrated that fibrinogen and creatinine are independent predictors of graft failure and HDL might be independently protective against graft failure and that diabetes was also independently predictive. ${ }^{4}$ Several SNPs of GST $\alpha 3$ were associated with graft occlusion, and expression of GST $\alpha 3$ was increased in the atherosclerotic regions of the human coronary arteries and tissues adjacent to the occluded bypass grafts.

Of the patients included in the present study, $29.9 \%$ had $\geq 1$ occluded study graft at angiography or CTA (2 patients had 2 occluded grafts). Because $8 \%$ of the patients ( 7 of 87 ) had clinical indications of myocardial ischemia prompting angiography, the incidence of graft failure was likely greater than in the overall post-CABG population. Consistent with our published findings, the vein grafts were much more likely to be occluded than the radial artery grafts. ${ }^{6,9}$ Improvements in SVG patency compared with historical data were likely largely owing to improved antiplatelet and lipid-lowering therapy. ${ }^{10,11}$ Intensive lowering of LDL cholesterol after CABG will reduce major cardiovascular events by $27 \%$ and repeat coronary revascularization by $30 \% .{ }^{11}$ More than $89 \%$ of patients in our study were treated with a statin-based lipid-lowering regimen preoperatively, and all patients were treated postoperatively, which was at least partly responsible for the high rates of LDL, triglycerides, and total cholesterol/HDL ratio within the targets determined from the current guidelines. ${ }^{8}$

In recent years, appreciation has increased for emerging biochemical and genetic risk factors as predictors of atherosclerosis and coronary events beyond the traditional Framingham risk factors. ${ }^{12,13}$ The promise of biomarkers is to facilitate the risk stratification of patients using a simple blood-based test. In the present report, we studied 12 plasma biomarkers with biologic plausibility that have been demonstrated to be strongly associated with cardiovascular disease in clinical epidemiologic studies. Of these, fibrinogen was independently associated with graft failure, and HDL was weakly protective.

Fibrinogen is a key regulator of thrombosis, and fibrinogen was an independent risk factor for cardiovascular disease. A meta-analysis of 154,211 patients from 31 prospective studies demonstrated that elevated fibrinogen levels were strongly associated with coronary artery disease (hazard ratio, 2.42; 95\% CI, 2.24-2.60). ${ }^{14}$ The fibrinogen levels themselves have been associated with inflammation and hemostasis. ${ }^{15}$

Clear epidemiologic evidence has shown that HDL is inversely related to coronary artery disease. An increase in HDL by $1 \mathrm{mg} / \mathrm{dL}$ was associated with a $2 \%$ reduction in coronary artery disease incidence in men and a $3 \%$ reduction in women. ${ }^{16}$ To our surprise, LDL and total cholesterol were not independent predictors of graft failure in our study. 
We also found that diabetes and high plasma creatinine were predictive of graft failure. The link among renal insufficiency, hypertension, and dyslipidemia has been demonstrated, even with mild renal impairment. ${ }^{17} \mathrm{~A}$ post hoc analysis of the Heart Outcomes Prevention Evaluation study found that the incidence of cerebrovascular death, myocardial infarction, or stroke was $22.2 \%$ with mild renal insufficiency compared with $15 \%$ with normal renal function. ${ }^{18}$ The precise mechanism linking elevated creatinine and graft failure could involve hypertension secondary to sodium retention, endothelial dysfunction, inflammation, and oxidative stress.

The strategies of linkage and candidate gene analyses and genome-wide association studies have already identified promising SNP associations with coronary artery disease and its major clinical sequelae, myocardial infarction. ${ }^{19-21}$ In the present study, we identified several novel SNPs that are potentially associated with graft failure, including 1 SNP in the 9p21.3 locus. In a large-scale genome-wide association study, SNPs in the 9p21.3 region were strongly linked to coronary artery disease, accounting for $10 \%$ to $20 \%$ of the population attributable risk. ${ }^{20}$ We also found several mutations of GST $\alpha 3$ to be associated with graft occlusion. Histologically, overexpression of GST $\alpha 3$ was found in human coronary atherosclerosis and tissues adjacent to occluded vein grafts. A member of the GST superfamily, GST $\alpha 3$ is a critical enzyme in detoxification of oxidative and xenobiotic agents. ${ }^{22}$ GSTs are upregulated in human atherosclerotic plaques, and GST-overexpressing endothelial cells are resistant to oxidative injury. ${ }^{23}$ Considering that oxidative stress and endothelial injury are key initiating steps in atherosclerosis, the observed expression of GST $\alpha 3$ could be a potential protective mechanism against graft failure. The identification of a critical gene or pathway associated with graft occlusion could lead to a novel therapeutic target, possibly by ex vivo gene transfer. In the Project of Ex-vivo Vein Graft Engineering via Transfection (PREVENT) IV trial, an E2F decoy was delivered to vein grafts intended for CABG, demonstrating the feasibility of such a therapeutic approach. $^{24}$

\section{Study Limitations}

Some important caveats exist related to our findings. We could not comment on whether the graft occlusion event occurred during the acute, subacute, or chronic postoperative stage. Furthermore, the biomarkers were measured at a single point, and, as such, the temporal expression profile is unknown. Thus, it is possible that alterations in biomarker expression occurred after graft occlusion and could not be used in a predictive algorithm. On univariate analysis, lower apolipoprotein B levels were associated with graft occlusion, a counterintuitive result that highlights the need for a panel of biomarkers and not any single biomarker in predictive algorithms. Because the patient numbers were small, our SNP data are preliminary and should be considered hypothesis generating.

\section{CONCLUSIONS}

In the present report, we have demonstrated that clinical variables such as diabetes and circulating biomarkers such as high fibrinogen, high creatinine, and low HDL are independent risk factors for graft occlusion after CABG. We performed an unbiased genetic association study that revealed an association between graft occlusion and mutations in the cardioprotective gene GST $\alpha 3$, a promising target for future investigation. The presence of clinical features and biochemical or genetic biomarkers associated with graft failure might identify patients who warrant closer follow-up, medical treatment, or novel graft-targeted gene therapy, ultimately offering greater patient-centered care.

The authors would like to thank Cheryl Crozier and Ye Sun at the Analytical Genetics Technology Centre, University Health Network, for their genomic support.

\section{References}

1. Loop FD, Lytle BW, Cosgrove DM, Stewart RW, Goormastic M, Williams GW et al. Influence of the internal-mammary-artery graft on 10-year survival and other cardiac events. N Engl J Med. 1986;314:1-6.

2. Greenland P, Knoll MD, Stamler J, Neaton JD, Dyer AR, Garside DB, et al. Major risk factors as antecedents of fatal and nonfatal coronary heart disease events. JAMA. 2003;290:891-7.

3. Campeau L, Enjalbert M, Lesperance J, Bourassa MG, Kwiterovich P Jr, Wacholder S, et al. The relation of risk factors to the development of atherosclerosis in saphenous-vein bypass grafts and the progression of disease in the native circulation: a study 10 years after aortocoronary bypass surgery. N Engl J Med. 1984;311:1329-32.

4. Kennedy JW, Kaiser GC, Fisher LD, Maynard C, Fritz JK, Myers W, et al. Multivariate discriminant analysis of the clinical and angiographic predictors of operative mortality from the Collaborative Study in Coronary Artery Surgery (CASS). J Thorac Cardiovasc Surg. 1980;80:876-87.

5. Marenberg ME, Risch N, Berkman LF, Floderus B, de Faire U. Genetic susceptibility to death from coronary heart disease in a study of twins. $N$ Engl J Med. 1994;330:1041-6.

6. Deb S, Cohen EA, Singh SK, Une D, Laupacis A, Fremes SE. Radial artery and saphenous vein patency more than 5 years after coronary artery bypass surgery. J Am Coll Cardiol. 2012;60:28-35.

7. Hosmer DW, Lemeshow S. Applied Logistic Regression. New York: John Wiley \& Sons; 1989

8. McPherson R, Frohlich J, Fodor G, Genest J, Canadian Cardiovascular Society. Canadian Cardiovascular Society position statement-recommendations for the diagnosis and treatment of dyslipidemia and prevention of cardiovascular disease. Can J Cardiol. 2006;22:913-27.

9. Desai ND, Cohen EA, Naylor CD, Fremes SE. A randomized comparison of radial-artery and saphenous-vein coronary bypass grafts. N Engl J Med. 2004; 351:2302-9.

10. Chesebro JH, Clements IP, Fuster V, Elveback LR, Smith HC, Bardsley WT, et al. A platelet-inhibitor-drug trial in coronary-artery bypass operations: benefit of perioperative dipyridamole and aspirin therapy on early postoperative vein-graft patency. N Engl J Med. 1982;307:73-8.

11. Shah SJ, Waters DD, Barter P, Kastelein JJ, Shepherd J, Wenger NK, et al. Intensive lipid-lowering with atorvastatin for secondary prevention in patients after coronary artery bypass surgery. J Am Coll Cardiol. 2008;51:1938-43.

12. Buckley DI, Fu R, Freeman M, Rogers K, Helfand M. C-reactive protein as a risk factor for coronary heart disease: a systematic review and 
meta-analyses for the U.S. Preventive Services Task Force. Ann Intern Med. 2009; 151:483-95.

13. Humphries SE, Drenos F, Ken-Dror G, Talmud PJ. Coronary heart disease risk prediction in the era of genome-wide association studies: current status and what the future holds. Circulation. 2010;121:2235-48.

14. Fibrinogen Studies Collaboration. Plasma fibrinogen level and the risk of major cardiovascular diseases and nonvascular mortality: an individual participant meta-analysis. JAMA. 2005;294:1799-809.

15. Woodward M, Rumley A, Welsh P, MacMahon S, Lowe G. A comparison of the associations between seven hemostatic or inflammatory variables and coronary heart disease. J Thromb Haemost. 2007;5:1795-800.

16. Gordon DJ, Probstfield JL, Garrison RJ, Neaton JD, Castelli WP, Knoke JD, et al. High-density lipoprotein cholesterol and cardiovascular disease: four prospective American studies. Circulation. 1989;79:8-15.

17. Culleton BF, Larson MG, Wilson PW, Evans JC, Parfrey PS, Levy D. Cardiovascular disease and mortality in a community-based cohort with mild renal insufficiency. Kidney Int. 1999;56:2214-9.

18. Mann JF, Gerstein HC, Pogue J, Bosch J, Yusuf S. Renal insufficiency as a predictor of cardiovascular outcomes and the impact of ramipril: the HOPE randomized trial. Ann Intern Med. 2001;134:629-36.
19. CARDIoGRAM Consortium, Samani NJ. Large-scale association analysis identifies 13 new susceptibility loci for coronary artery disease. Nat Genet. 2011; 43:333-8.

20. Helgadottir A, Thorleifsson G, Manolescu A, Gretarsdottir S, Blondal T, Jonasdottir A, et al. A common variant on chromosome 9p21 affects the risk of myocardial infarction. Science. 2007;316:1491-3.

21. McPherson R. Chromosome 9p21 and coronary artery disease. $N$ Engl J Med. 2010;362:1736-7.

22. Yang $\mathrm{Y}$, Trent MB, He N, Lick SD, Zimniak P, Awasthi YC, et al. Glutathione-S-transferase A4-4 modulates oxidative stress in endothelium: possible role in human atherosclerosis. Atherosclerosis. 2004;173:211-21.

23. Yang Y, Yang Y, Xu Y, Lick SD, Awasthi YC, Boor PJ. Endothelial glutathioneS-transferase A4-4 protects against oxidative stress and modulates iNOS expression through NF-kappaB translocation. Toxicol Appl Pharmacol. 2008; 230:187-96.

24. Alexander JH, Hafley G, Harrington RA, Peterson ED, Ferguson TB Jr, Lorenz TJ, et al. Efficacy and safety of edifoligide, an E2F transcription factor decoy, for prevention of vein graft failure following coronary artery bypass graft surgery: PREVENT IV: a randomized controlled trial. JAMA. 2005;294: 2446-54. 


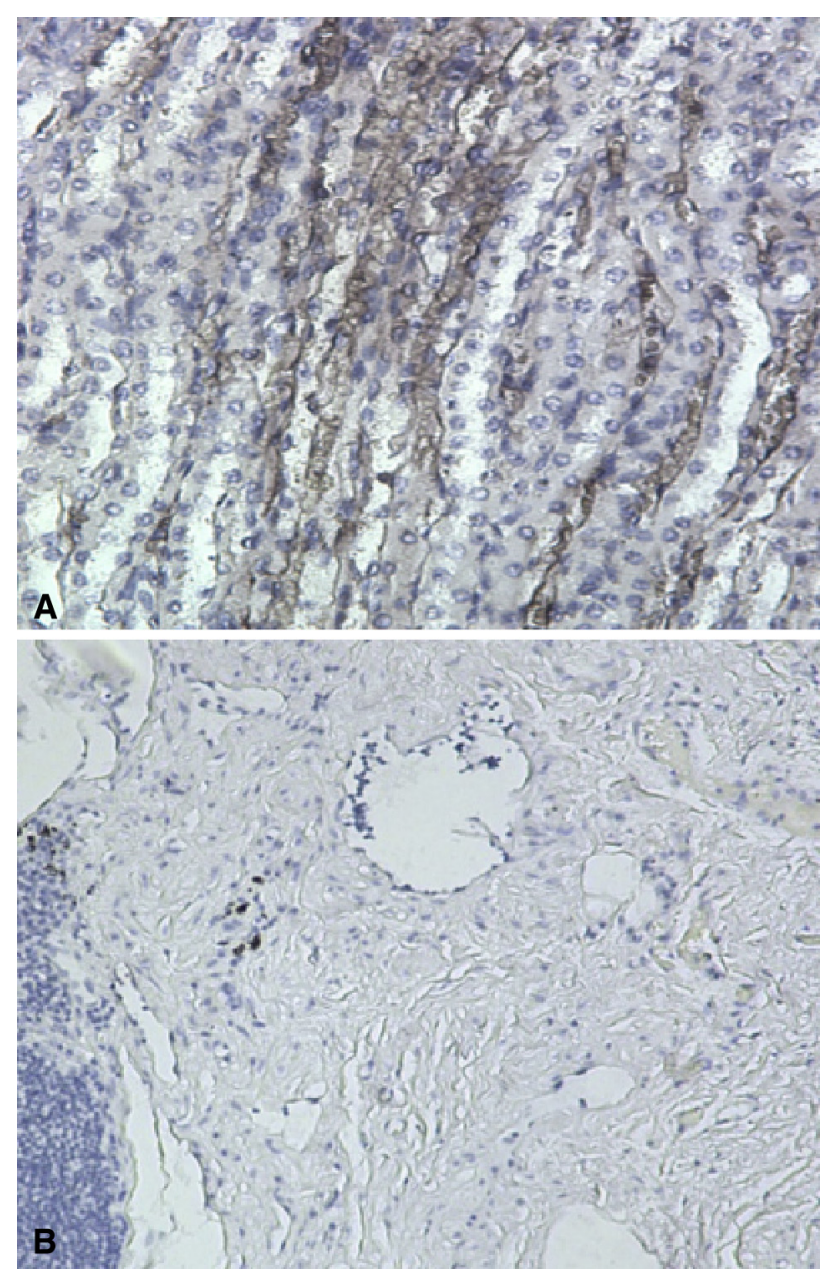

FIGURE E1. Positive and negative immunohistochemical controls for glutathione-S-transferase $\alpha 3$ expression. A, Murine kidney was used as a positive control (original magnification $\times 40$ ) and $\mathrm{B}$, a section of human saphenous vein graft as a negative control (original magnification $\times 20$ ). 
TABLE E1. Human SNPs associated with graft occlusion in patients undergoing isolated CABG

\begin{tabular}{lrrrrlll}
\hline \multicolumn{1}{c}{ SNP } & Ch & Location & OR & $\boldsymbol{P}$ value & Allele & \multicolumn{1}{c}{ Symbol } & \multicolumn{1}{c}{ Annotation } \\
\hline rs279553 & 3 & 9909605 & 0.1 & $6.2 \mathrm{E}-05$ & $\mathrm{~A} / \mathrm{G}$ & JAGN1 & Jagunal homolog 1 \\
rs1805124 & 3 & 38620424 & 5.1 & $8.4 \mathrm{E}-05$ & $\mathrm{G} / \mathrm{A}$ & SCN5A & Voltage-gated Na channel type V- $\alpha$ \\
rs1330927 & 9 & 23421906 & 0.1 & $9.1 \mathrm{E}-05$ & $\mathrm{~A} / \mathrm{C}$ & LOC402360 & NOP56 ribonucleoprotein $(9 \mathrm{p} 21.3)$ \\
rs1541221 & 1 & 34556271 & 6.7 & .0001 & $\mathrm{~A} / \mathrm{G}$ & C1orf94 & Ch 1 open reading frame 94 \\
rs588565 & 6 & 52900813 & 6.0 & .0001 & $\mathrm{~A} / \mathrm{G}$ & GSTA3 & Glutathione S-transferase $\alpha 3$ \\
rs4705334 & 5 & 145802708 & 8.0 & .0002 & $\mathrm{~A} / \mathrm{G}$ & TCERG1 & Transcription elongation regulator 1 \\
rs722212 & 4 & 11004173 & 11.4 & .0002 & $\mathrm{~A} / \mathrm{G}$ & HS3ST1 & Heparan sulfate 3-O-sulfotransferase 1 \\
rs2996053 & 21 & 40312865 & 5.4 & .0002 & C/A & DSCAM & Down syndrome cell adhesion \\
rs602195 & 6 & 52908028 & 5.6 & .0002 & A/G & GSTA3 & Glutathione S-transferase $\alpha 3$ \\
rs1886551 & 13 & 98364436 & 0.2 & .0002 & G/A & DOCK9 & Dedicator of cytokinesis 9 \\
rs10507257 & 12 & 114172785 & 4.3 & .0002 & G/A & TBX3 & T-box 3 \\
rs373552 & 6 & 52909987 & 5.6 & .0003 & G/A & GSTA3 & Glutathione S-transferase $\alpha 3$ \\
rs378411 & 6 & 52912763 & 5.6 & .0003 & G/A & GSTA3 & Glutathione S-transferase $\alpha 3$ \\
rs3823104 & 6 & 2728984 & 0.3 & .0003 & A/C & WRNIP1 & Werner helicase interacting protein 1 \\
rs17459166 & 7 & 16268375 & 0.2 & .0003 & A/G & hCG_1745121 & Isoprenoid synthase domain \\
rs651733 & 6 & 52897787 & 5.2 & .0003 & A/G & GSTA3 & Glutathione S-transferase $\alpha 3$ \\
rs3801734 & 7 & 81624853 & 4.6 & .0004 & G/A & CACNA2D1 & Voltage-gated Ca channel $\alpha 2 /$ delta-1 \\
rs4980684 & 11 & 69249908 & 0.2 & .0004 & A/G & FGF19 & Fibroblast growth factor 19 \\
\hline
\end{tabular}

$C A B G$, Coronary artery bypass grafting; $S N P$, single nucleotide polymorphism; $C h$, chromosome; $O R$, odds ratio. 